\title{
Water and Polymers: Nature's Biofilms and Synthetic Plastics
}

\author{
Louis ZG Touyz* \\ Faculty of Dentistry, McGill University, Canada \\ *Corresponding author: Louis ZG Touyz, Faculty of Dentistry, McGill University, Montreal PQ, Canada, Email: touyzlouis@gmail.com
}

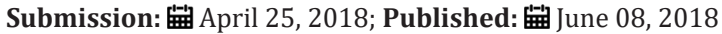

\begin{abstract}
Introduction: Formation of natural biopolymers impacts all levels of biology. Mainly found in water biology, marine and aquatic ecosystems are fundamental into the understanding of water management. From antibiotics and microbes, to sub-aquatic slimes in Nature, polymers influence most biological ecosystems affecting Mankind.
\end{abstract}

Aim: This paper appraises ubiquitous biofilms at macro-and microscopic levels all of which have a marked effect on all living things in most biospheres.

Discussion: The importance, formation, function and management of exo-polymer matrices are deconstructed and the powerful functional outcomes of growing natural, and abuse of synthetic polymers, are discussed. Natural polymers and synthetic manufactured polymers are different, in that natural polymers are continuously broken down biologically but most synthetic polymers do not decompose and fracture down to micro-plastic particles. Natural polymers may affect microbial metabolism and water pollution, but synthetic plastics at the macro-and micro-levels cause ongoing toxic water pollution.

Conclusion: Polymers in nature play a vital role in biology; synthetic polymers are toxic to the oceanic food chain. Improved understanding of their formation, and life cycles may mollify and negate unwanted destructive side-effects impacting Mankind. Synthetic plastic polymers present a danger to global fauna.

Keywords: Antibiotics; Biofilms; Biospheres; Ecology; Ecosystems; Exo-polymers; Enzymes; Glucans; Extra-cellular-polymers; Matrices; Microbes; Micro-plastics; Plastics; Poly-saccharides; Transferase

Abbreviationsc: BP: Biological Polymers; CE: Climax Ecosystem; CF: Combination Filter; ECP: Extra-Cellular+Polysaccharide; Exo-P: Exo-Polymer; EPA: Environment Protection Agency of USA; EPS: Extracellular Polysaccharide; GT: Glucosyl-Transferase; FT: Fructosyl Transferase; GT: Galactosyl Transferase; MP: Microplastics; PE: Primary/Pilot Ecosystem; SSF: Slow Sand Filter; RSF: Rapid Sand Filter; SPP: Synthetic Plastic Polymers; NBP: Natural Biological Polymer; MP: Micro-Plastics

\section{Background and Introduction}

Currently a growing fashion exists to drink 'pure raw water.' People locate natural sources of flowing water and draw large volumes from the source, in the belief that 'natural raw' water is healthy and naturally filters out all pathogens. In some sources this may be true, but many sources are polluted with viable bacteria which survive in sessile growing colonies or as floating planktonic clumps in the water. Biofilms, which are polymer networks, are ubiquitous in Nature and are found within and on, most living organisms. Polymer biofilms consist of bacteria enmeshed in layers of mucilage adhering to an organic or inorganic surface [1]. Biofilms allow for the rapid sharing and spread of microbial genetic material between diverse component microorganisms. Biofilm formation, thriving in a polymer matrix can have serious implications in industrial, environmental, medical and public health situations. Petro chemicals exploit polymer chemistry and create many new synthetic plastic polymers Synthetic plastics (SPP) are also polymers are mostly man made, and are also affecting the environment and the health of the world. Single use products made from (mostly shale) gas, like polypropylene, polyethylene and others, are globally ubiquitous, and most products are not easily biodegradable.

\section{Aim}

This appraisal assesses the world-wide nature of polymers in (1) natural- and (2) synthetic-domains, micro- and macro-scopic levels.

Natural organic polymers and microbes in natural (nonOceanic) water-ways:

A. Provenance of bio-polymers: Natural biofilms are polymers which behave as a dynamic ionic exchange gradient with 
unique properties. The following discussion focuses on its locations and formation inland and marine waters; it's changing ecosystems; its structural architecture; it's electro-chemical ability to modify acidity and osmotic strength; it's dynamic ability to sustain growth and nutrition of constituent microbes, the ability to exchange genetic material, and its impact on infecting waters affecting humans and other organisms in related biospheres [2].

The microbiology of natural waters is very complex and relies heavily on bio-polymers to sustain its flora. Ecosystems enmeshed in natural bio-polymers (NBPs) thrive mainly in shallow, sun-heated waters, close to land and in proximity to sewage-disposal outlets. Bacteria grow ubiquitously, in all places in Nature where viable microbes in water are found. A bacterial biomass from selected microbes may grow in or upon any continuously water covered moist surface. The prevalence and types of micro-organisms in natural water depends mainly on nutrients available, the aquatic environment, other organisms present and some important physical factors [3]. Most critical are the micro-nutrients needed in the water: for example: iron $\mathrm{Fe}+++$ for specific 'iron bacteria'; $\mathrm{H}_{2} \mathrm{~S}$ for Sulfur oxidizing microbes; $\mathrm{CH}_{4}$ for methane oxidizers; and decaying organic animal and vegetable matter for organophyllic saprophytes. Most natural water sources also contain most of the minerals needed for microbial growth [4]. Dissolved substances in water tend to accumulate on solid surfaces and in small lacunae, niduses and micro-gaps.

Most microbes develop a glycocalyx on their surfaces, which is essentially a type of polymer, as a muco-polysaccharide or biological polymer (BP). Many of these micro-environments also exist in porous materials, in which the metabolic products from micro-organisms can accumulate. Consequently the widest array of many microscopic plants and animals are found and thrive in microniches on the bottoms, on the banks and close to the shores of most waterways. (In the sea numbers of micro-organisms and bacteria are most frequently found within a few miles from land, river outlets other organic matter dumping sites. See below comments on Natural Oceanic waters) [5]. Accordingly microbes will grow in ponds, pools, dams, lake and river-beds, on any object or substance with micro-loci found in cluttered contaminated waters, and close to the shores. For example microbes will grow and form colonies, many with biofilms (NBPs), on the surfaces of stones, rocks, sandy sediments, and sunken organic matter in rivers and ponds, on the water-beds, on objects floating in- and on- the water, as well as in water outlets of pipelines. Some waters may contain unfavorable substances which affect bacterial growth [6].

Acidogenic industrial waste combined with metallic tailings are not only lethal for micro-organisms but also toxic to many aquatic plants, fish and creatures among the most critical physical factors are the micro-nutrients needed in the water. The change in acidity $(\mathrm{pH})$ from Sulfuric acid $\mathrm{H}_{2} \mathrm{SO}_{4}$ from industrial waste, or production by sulfur-oxidizing microbes, organic acids, various fermentation processes, in muds and stagnant oozes which negatively affects the growth of bacteria and many micro-organisms. The microscopic fauna and flora in natural waters are inter-dependant for survival. For example most planktonic organisms cannibalize themselves, feed on available bacteria and on algae, and maintain for themselves a balance between life and death. Bacteriophages and Protozoa and other predators like Bdello-vibrio will survive by destroying innumerable (in billions) of bacteria. Bacteriophages specific for marine microbes, may use unique antibiotics or other bacteriocidal molecules (bacteriocins) to achieve their success.

The physical features impacting waters and the NBPs which are most important remain the quantity and quality of microbes in water; these microbes will inexorably be dictated to a large extent by $\mathrm{pH}$ (acidity); the osmotic pressure (derived from ionic salinity); hydrostatic pressure (from depth of the water) and the penetration of sunlight (source of energy and photosynthesis) [7].

All fresh surface water is seeded with bacteria from dust, falling rain-draining-flows off adjacent land surfaces. These microbes grow as indigenous species in the water but are diluted and kept low from continuous flow. Various species of soil microbes can survive as floating planktonic colonies within a sticky NBP in the mineral and organic content of unpolluted water; saprophytes like Micrococcus, Flavobacterium; Achromobacter, Bacillus, Proteus, Pseudomonas, and Leptospira are present. Decaying organic matter allows sessile growth colonies of Clostridium species, and other anaerobic \& facultative bacteria, like sulfur bacteria and sulfate reducing species (Desulfovibrio). "Algae-like" organisms like Chlamydobacteriales \& Caulobacteriacae may grow on rocks close to shores. Rhodobacteriinae are photosynthetic bacteria that will metabolize hydrogen sulfide (from anaerobic breakdown) of sunken organic matter [8].

\section{Changes in aquatic ecosystems}

Newly drowned biological materia, like a huge tree landing on a shallow lake bottom, stirs up the microbial equilibrium and changes the ecosystem almost immediately. The bottom flora yields various saprophytes, such that those exposed deep-buried organisms thrive and dominate, increasing bacterial counts to over $100,000 / \mathrm{ml}$. However in mountain streams, above the tree line with low organic falls, reveal much lower bacterial counts. The flowing water mitigates against NBP formation [9]. Also the low temperatures and lack of nutrients slow down germination of spores from ubiquitous molds, yeasts, Bacillus, Streptomycetaceae. But a few other bacteria introduced from dust, may be present such as micrococci, diphtheroids, or gram-negative rods derived from snow or rain carrying these from adjacent soil. Psychrophylics, (organisms which grow best at low temperatures 0 to $32{ }^{\circ} \mathrm{C}$; (32$86{ }^{\circ} \mathrm{F}$ ), with optimum growth at $15-20{ }^{\circ} \mathrm{C},\left(59-68{ }^{\circ} \mathrm{F}\right.$ ) are most numerous among the stream flora.

\section{Microbes in polluted water-ways}

Dead animals and birds, animal excreta, insects and sewage dumping all may pollutes pristine waters with infectious material including much human waste and feces. In the wet muddy ooze which has a low oxidative/reduction potential and anaerobic 
species such as Clostridium, Desulfovibrios, and other anaerobes and facultative microbes thrive, form NBPs, and are responsible for degradation of much of this biological material.

Enterobacteriaceae may be found in profusion; species include Shigella, Escherischia, Klebsiella, Streptococci, Clostridium, Proteus, Vibrio and Salmonella. Consequently fecal contamination of potable drinking water is responsible for epidemics of gastro-intestinal diseases like cholera, dysentery and other digestive diseases, when polluted waters are used for drinking. The fecal pabulum mixed with mucopolysaccharides (NBPs), allows many soil saprophytes like Spirillum, Darcina, Micrococcus, Mycobacterium, Bacillus, yeasts, molds, Leptospira, Spirochetes, Beggiatoa, Sphaerotilus and many other fungi and algae-like organisms to grow.

Polluted waters change their bacterial make-up quickly in response to tide flows and more dumping. Drain flushes after storms, effluent dumping by large luxury cruise liners, run-offs from pig-factory farms, fecal disposal as fertilizer are all examples of what can induce sudden changes and concentration of pathogens, in polluting water. Saprophytes scavenge and metabolize organic waste [10]. They make metabolites available for other organisms in the water, like protozoa, algae, worms and aquatic flora and Aerobic organisms (non-putrefactive and non-fermentative). Too much waste depletes the biologically available oxygen for ongoing aerobic breakdown, and should anaerobic fermentation and putrefaction obtain and predominate, foul odors and growth of anaerobic bacteria become prevalent with undesirable sequaelae (stenches, infections, epidemics etc).

Algae are photosynthesizing single or multi-cellular plant forms that grow globally in water ways. Often referred to as "Blooms", they are also labeled as blue-green algae; or red tides. Cyanobacteria are mistakenly called algal blooms. Algal blooms can also be caused by haptophytes, dinoflagellates, green algae, raphidophytes, euglenophytes, diatoms and cryptophytes, but though they can be a nuisance, they do not produce toxins like cyanobacteria [11]. They all grow polymer mucilaginous glycocalyces which is sticky and allow colony formation. One common algae species is spirogyra, but there are many others like Chlorella and Euglena. Algae may be benign to humans and animals.

Certain cyanobacteria produce alkaline phosphatase enzyme, which facilitates release of phosphorous from organic sources. Common Cyanobacteria species include Anabaena, Aphamizomenon, Aphanothece, Microcystis, Oscillatoria, Cylindrospermopsis and Geotrichia. Many of the species may grow in sea and fresh water. Cyanobacteria-like nitrogen-fixing Cyanobacteria anabaena, Nodularia, Nostoc, Gloeocapsa, Trichodesmium, \& Synechococcus will produce toxic blooms in nutrient rich Phosphate/Nitrates in water from untreated sewage, wastewater, or agricultural runoffs. 100,000 cells/ml, is accepted by WHO as a moderate human health hazard and risk. Birds pollute fresh waters by introducing algae species which could be toxic, for example Cylindrospermopsis raciborskii is a type of cyanobacteria. Produced toxins include Saxitoxins, Anatoxins, Microcystins, Cylindrospermopsins, \& Aplysiatoxins, all of which maybe toxic to animals on land and sea, including humans. They may be neuro, hepato, dermato, gastrointestinal and/or cytotoxic in action [12]. All these microbes produce tenacious exopolymers which allow and promote growth, seeding and pollution of all bodies of water.

\section{The harmful effects of algal blooms may affect ecological humans and/or land and aquatic organisms}

Ecological: Algal blooms affect the food chain by depriving nutrients for phytoplankton that zooplankton use to thrive. This starvation decreases food for higher animal orders. Surface cell growth may block sunlight from primary producers under water, causing a reduction of nutrients, energy and oxygen levels. Overgrowths decrease dissolved oxygen levels which become deadly to aquatic organisms and cause major fish kills. Low levels of dissolved oxygen in waters are aggravated by inclement cloudy weather and rising temperatures. This may disrupt whole aquatic ecosystems.

Humans and animals: Not only may this impact recreational use because of toxicity from mats of algae, but also odors from decaying blooms are offensive. Cyanobacteria blooms foul the taste of potable waters, with malodorous volatile sulfur compounds, potent toxins. The toxic blooms yield human cyanobacteria neurotoxins. Cyanobacteria may be lethal to wild waterfowl, livestock, and dogs after eating the growth or licking their fur after immersion in infected waters. Human deaths are known to have been caused after exposure to harmful algal blooms [13].

Lakes and open reservoirs may be contaminated by the harmful alga bloom toxins. The removal of cyanobacteria toxins is challenging. EPA authorities are researching methods to ameliorate toxin removal with existing methods by re-locating where treatment chemicals are applied, the quantity and quality of chemicals applied, and the acidity (optimal $\mathrm{pH}$ ) at which the processes are operated [14]. The current systems researchers are examining the effects of $\mathrm{pH}$, hydrogen-peroxide (H2O2) addition of ozone-contact efficiency. Human pollution from discarded medications (hormones drugs etc) is becoming an added toxic burden which may affect natural waters, and this demands future attention of water engineers.

Natural oceanic waters: The seas and oceans are classified into zones; the benthic (relating to the floor) and the pelagic (the upper surface layers), the oceanic (the open sea), the neritic (coastal water not more than 200meters deep), the littoral (the beach or inland tidal waters), the euphotic (sunshine exposed) and the aphotic (dark) without sunlight, zones. Bio-nutrients are more plentiful close to euphotic littoral zones and consequently a richer quantity and variety of all biological species are frequently found there.

Acid producing industrial wastes act agonistically with metallic tailings are most toxic and lethal for oceanic micro-organisms, marine plants, fish and sea creatures. The prevalence of microorganisms and bacteria in the middle of inland lakes and far out at sea (oceanic microflora), are diluted by the sheer volume of water, 
so that bacterial counts are miniscule by comparison to fauna and flora close to shores and littoral waters. Although some species of bacteria have adapted to living in sea-water, a high salinity inhibits growth of most microbes, as is witnessed in The Dead Sea, and this property is used to pickle and preserve foods like meats; $\mathrm{H}_{2} \mathrm{~S}$ derived from organic matter also inhibits bacterial growth [2]. A few rare Dead Sea species are halophilic (needing 13\% w/v) salt to survive. Common marine microbes need sea-water to grow, and these marine microbes are stenohaline, with narrow and a distinctive, specific need for sodium $(\mathrm{Na}+)$ and other sea-water ions to thrive. These marine species are osmotically sensitive, but retain the same properties as familiar terrestrial species. They live in water temperatures ranging from $40{ }^{\circ} \mathrm{C}$ in the tropics to $-2{ }^{\circ} \mathrm{C}$, a super-cooled temperature at which water will freeze to ice, in the polar regions. In tidal bays, and oceanic lagoons many Spirillum species are found, and are osmotically protected by necessary sea water salinity. These organisms are very small $(\sim 0.22 \mu)$ and need micro-filters no bigger than the measure, to be effective at stopping them passing through [4].

Depth and temperatures of oceans: In deep oceanic trenches, one to three miles or more deep, barophilic bacteria grow in water at $3{ }^{\circ} \mathrm{C}$. Sources of energy are not directly from sunlight, and at those depths the pressure can be as much as 2000psi or more. Some organisms are thermophilic and grow near sub-aquatic volcanic vents at temperatures of $40-50{ }^{\circ} \mathrm{C}$. Some microorganism has thermoluninescent properties and maybe ingested by marine animals. Photobacterium phosphorum and Vibrio pierantonii grow in sea water and will grow and glow inside fish bodies when ingested. Few if any of these organisms are in neritic or littoral waters, but other common aerobic and anaerobic species are carried by birds, fish and ocean currents as organisms or spores, and the latter are found in polar and neritic waters [6].

Oceanic waters are not sterile, and besides being the natural environment and ecosystems for a myriad of aquatic species and many schools of fish and their predators, a wide range of marine and aquatic fauna and flora exist at all levels. Marine diatoms act like the grass of the oceans and they metabolize trace nutrients by the mega-ton. Many diatoms in the neritic levels use sunshine and microorganisms to digest food supply, and are always present often in small numerical dilutions [14]. Dead diatoms leave behind insoluble calcium/silicate exoskeletons and sink to the depths of oceans; with evolutionary geo-terrestrial migration of continental plates, large deposits of these dead organisms are found as 'Diatomaceous earth," which collectively was once at the bottom of ancient defunct seas.

Procuring safe clean drinking water: Among the many challenges facing civilization is the provision of safe clean drinking water to farms, villages, towns and cities. The earth acts as natural filter and seepage, rain and underground water reserves act as natural disinfecting mechanism, and many, but not all, wells, springs and flowing rivers yield safe drinking water [11]. These traditional sources of water become polluted through seepage and drainage from infected sources in agriculture and urban living. Bodies of water close to human habitation become convenient dumping grounds for sewage and whenever fecal contamination of drinking water occurs, epidemics of disease become prevalent. For example, after the 2016 hurricane floods in Haiti, epidemics of "cholera" dysentery broke out from Vibrio cholera originating in sewage, which infected the drinking water supplies. Accordingly water designated for domestic use in many cities and towns are collected in reservoirs and the water is filtered, cleaned, disinfected and rendered safe before release. Where fresh supplies of water are scarce recycling sewage is successfully employed.

Water filtration plants are civil engineering challenges. In general the process involves (i) Sedimentation and Flocculation; (ii) Filtration and; (iii) disinfection. Unless the water is taken from a naturally filtered source, the polluted water is impounded in large collecting reservoirs and the silt, and organic matter (dead animals, foliage, vegetable matter etc) are allowed to settle on the bottom. The supernatant water is then piped to a filter plant where sticky substances like Ferric Sulfate $\left(\mathrm{FeSO}_{4}\right)$ is added. This forms a tenacious flocculent precipitate which sinks to the bottom, taking with it most of the biological, vegetable matter many bacteria and residual organic detritus. The water is then piped through sand-filters of which there are several types: (a) The slow sand filter (SSF); (b) The rapid sand filter (RSF)and (c) Combination processes (CF: tank machines and package plants). The SSF has large sand and gravel beds, on an acre or more in area, built over porous drain pipes, commencing with coarse base gravel followed by progressively smaller grained sand, with the finest sand on top. Water is allowed to seep through slowly and filtration proceeds continuously and the bacteria form a slimy, gelatinous polymer film allowing many millions of bacteria, protozoa and other microorganisms to grow. This mucilaginous film gradually reduces the spaces between the sand grains, and progressively makes the filter more effective. The upper few centimeters of the sandy layer is called the Schmutzdecke (German for dirt layer: see below), which is microbial formed molecular exo-muco-polysaccharides that help close up the pores between the sand grains. This matrix allows for highly active biological processes to take place by inhabiting protozoa and bacteria, and this effectively greatly reduces the chemical and bacterial content [15]. Ongoing monitoring bacterial counts are vital at all stages of the filtration. SSF can yield as much as 300000 (three million) gallons of water per acre per day. Depending on the microbial load of the source feeding-in water, the life-time of a SSF varies [16]. When this slimy layer becomes too thick, it yields threshold warning bacterial-counts, and then the plant is stopped, the discarded filter is emptied of water and the slimy polymer layer removed and replenished with fresh gravel and new sands.

The RSF works on a similar principle but large volumes of water are forced through multiple sand filters and is not dependant on the formation of a schmutzdecke. The sand filters fragment and remove all the bacterial Exopolymers and most of the bacteria. RSF are erected in repeat units, as a battery of filters, and the sand is 
washed regularly with clean water. RSF can yield 130000000 (one hundred and thirty million) gallons of fresh water per acre per day. Economics, space available, hydro-management skills, expert civil engineers, microbiologists, testing laboratories and chemical lab facilities, and qualified staff are all necessary pre-requisites to have a SSF and RSF; these factors are often constraints as to whether to implement a RSF. A SSF is cheaper to run.

Chlorination disinfection: Both SSF and RSF do not yield sterile water. To be made potable the polluted water must be disinfected to eliminate all pathogenic organisms including protozoa, all bacteria and viruses. Viruses are obligate parasites and need a living cell to survive; accordingly the disinfection process must eliminate all living cells which will include all viruses. Numerous (over 70) viruses found in the water include ECHO, Coxsackie, Polio, hepatic and adeno-viruses. Heavy chlorination will eliminate these viruses. Gastro-intestinal parasites pathogenic to animals and humans [like: Ascaris lumbracoides, Taenia species (tape worms), Amoeba Giardia, Trichuris, Diphyllobothrium, Enterobius, Schistosoma, and other species ] as well as the Pathogenic entero-bacteriaceae microbial species [such as Shigella, Eshchrishia, Klebsella, Salmonella, Proteus, fecal Streptococci, Clostridium, Bacteroides, Cytophaga, Micrococcus, Pseudomonaceae, Spirochetes, Achromobacteraceae, yeasts, saprophytes and Vibrio] must be removed or killed. This is achieved by chlorination; chlorine is added t till all organic matter is saturated (breakpoint chlorination), totally denatured and killed. Chlorine is added in various ways for example donors like dichloroisocayanourate, and other chlorine containing chemicals are added, which effectively kills off all biologically viable organisms. Enough is added to ensure a residual of $0.2 \mathrm{mg}$ to $1.0 \mathrm{mg}$ of free chlorine per liter of water (the residual chloride one part per million per liter water) [17]. At this level the organoleptic residual smell of chorine is minimal and chlorination effectively eliminates any possibility of bacterial dysentery or transmission of parasite $s$ in the potable water.

Fluoridation of municipal potable water: Fluorides occur naturally in earth and may be found in high concentrations (over $1.2 \mathrm{ppm}$ and higher) in borehole-, well and subterranean-waters. It is present in fish and infusions of tea. Ongoing imbibing of fluoride at over $1.5 \mathrm{ppm}$ will damage biological calcification processes like bone and tooth formation and calcification. This toxic dose of drinking water, results in deforming dental fluorosis, and brittle bone disease. As with most substances, the dose makes the poison, and this applies to fluoridation of potable water. Fluoride as an anion of naturally occurring fluoride salts has been added safely to municipal drinking waters for over six decades (since 1940's to current). Fluoride does not demand use of energy to cross biological membranes, and quickly diffuses across biological membranes from higher to lower concentrations in muco-polysaccharides until equilibrium of ions is reached. Calcium Fluoride $\left(\mathrm{CaF}_{2}\right)$ is insoluble at neutral $\mathrm{pH}$, so fluoride as $\mathrm{NaF}$ is added to the water to reach between 0.7 and 1 ppm (one part per million; or $1 \mathrm{mg}$ per liter). For dental decay to start the main calcium salt in dental hard tissues
(Calcium hydroxyapatite) needs to be decalcified, and subsequent cavitation by bacteria, causes dental caries. The critical $\mathrm{pH}$ for calcium-hydroxyapatite decalcification is between $\mathrm{pH}$ 5.5and 6.5, a $\mathrm{pH}$ level easily reached with acidogenic diets. With available fluoride ions, calcium fluoride $\left(\mathrm{CaF}_{2}\right)$ is formed at critical starting dental niches (pits and fissure and interdentally) which is more resistant to decalcification at $\mathrm{pH} 5.5$. The critical $\mathrm{pH}$ for dissociation of $\mathrm{CaF}_{2}$ to $\mathrm{Ca}+$ and F- ions is below pH3, and decalcification is slowed significantly. The direct consequent cause and effect result is a reduction of tooth decay in populations of up to $80 \%$. Dental biofilm provide many loci for Pilot Ecosytems to change to Mature Ecosystems (see below) with changes in microbiology that promotes decay formation and gum disease. Fluoride ions, introduced in the drinking water, diffuse freely through the exo-polymer and inhibits bacterial growth as well as hardening the surface and sub-surface hard tissue with acid resistant $\mathrm{CaF}_{2}$. Fluoridation at $1 \mathrm{ppm}$ is referred to as eufluoridation; at this concentration the organoleptic properties (taste and smell) are negligible.

Many cities have separate systems for sewage disposal and storm water drainage. Industrial waste from dairies, tanneries, paper mills are often disposed of on sight at the facility, and demand chemical engineered plants to minimize pollution oozing from their tailings [3]. Mercury and lead are the two main putative chemicals involved, but others also (like chromium from leather tanneries) may be implicated.

Sewage treatment and disposal is a specialized field of water management and recycling, involves different specifically purpose built systems like Imhoff processor tanks, industrial chemical plants, and/or septic tanks etc, and demands separate comment. This is a highly specialized field and much progress at managing sewage has materialized over recent centuries. This will not be discussed further in this appraisal and readers are referred to resources covering this field.

\section{How do bacteria form exo-polymers found in schmutzdecke?}

Many microbes have specific DNA programs for synthesis of transferases. Specific mono-saccharides are transformed by their appropriate transferase into polymeric chemically linked chains. Accordingly there is glucosyl-transferases (GT), fructosyltransferase (FT) and galactosyl-transferase (FT); these protein enzymes promote chemical linking of carbohydrates from individual uni-molecular structure to larger, longer con-joined molecules [5]. These reconstructed molecules are referred to as polymers of the constituent uni-molecules (monomers). Accordingly glucose will be transformed into glucans, and fructans, galactans are among the other polysaccharides which contribute to the mix of the formed mucous. These saccharides polymers are pushed out of forming bacteria by a process called 'exocytosis' and accumulate on the exterior of cell membranes.

Cellulose itself is a polysaccharide (polyglucose), mainly from vegetation origin, will be broken down by bacteria with the enzyme 
cellulase, and the cellobiose residues reconstituted as mucilage polysaccharide. Methyl cellulose is one example of a reconstituted polysaccharide. These mucoidal products are clear viscid liquid secretions. The accumulated slimy mucous is referred to as exopolymers or extra-cellular polysaccharide, or mucous matrix, and are an intrinsic part on the outer exterior of biological membranes called the 'glycocalyx'. The molecules ionize in the matrix into positive (+ve) and negative (-ve) ions, with the outer surfaces of the matrix become negatively charged. These charges are receptive to positively charged ions in the surrounding liquid. This mucopolysaccharide is a slimy liquid with stretching properties derived from surface tension of adhering long chain molecules; this extending property is referred to as 'spinbarkheit'.

Are all biofilms the same? No, biofilms are not all the same. Fresh newly formed biofilms have different microbial properties when compared to older stagnated mature biofilms. The biofilms consist of changing ecosystems of bacteria and are graded as primary/ early (PE), intermediate (IE) and climax/mature ecosystems (CE). The PE's form and allow other planktonic Gram negative species to seed, gain hold and become sessile colonies. The IE's and CE's are found in the deeper layers under layers of exo-polymers in all micro-niches and covered surfaces, which act as a rich mucilaginous matrix for seeding, multiplication and metabolism for most of the constituent bacterial biomass.

\section{Grading stages of ecosystems}

PE's are mainly aerobic, are Gram positive organisms, nonmotile, exo-polymer producing adhere to surfaces as sessile colonies and also seed planktonic colonies. These ecosystems take hold and form colonies will form within days. (See below)
IE's are transformative stages with aerobic, facultative and anaerobic organisms. They allow anaerobes to stick and proliferate within the accumulated glycocalyces of Gram-positives. CE's are mainly anaerobic, Gram-negative species, motile (rods, spirally and vibratos) grow well in the matrix and provide excellent pabulum for other species. A syntrophism develops in CE's, allows for multiplication in the ECP, and thereby also adheres to surfaces as intra-mucus clumped colonies that also seed planktonic floaters. (See below).

The syntrophism allows bacteria to thrive and exchange genetic information. The biomass as a biofilm allows flow channels to develop for fluids, dynamic exchanges of nutrient molecules and ions, control of $\mathrm{pH}$ and precipitation, when conditions allow (changes in $\mathrm{pH}$ with active $\mathrm{Ca++},-\mathrm{PO} 4---$, -carbonate -C03, or fluoride $\mathrm{F}^{\prime}$ ions) which results in encrusted calcified deposits on surfaces.

The schmutzdecke is essentially a mature multilayered ecosystem within a stretch of polysaccharide mucus, housing structured layering of mixed organisms, with surface aerobes and multiple layers of anaerobes underneath.

Formation of biofilms: Early biofilms are formed by allowing negatively charged bacteria adhering to a negatively charged surface. Metal and other minerals will have a minute micro-voltage charge which makes them suitable sites for microbial attachment. This is achieved by divalent ions (like magnesium $\mathrm{Mg++}$, calcium $\mathrm{Ca}++$, and others) and positively charged organic molecules or proteins $(\mathrm{Pn}++$, such as proline rich proteins, lectins, aniline rich proteins, statherin and lipoteichoic acids). When the early bacteria attach and start forming an exo-polymer this is referred to as a primary or Pilot Ecosystem. (PE) See Figure 1.

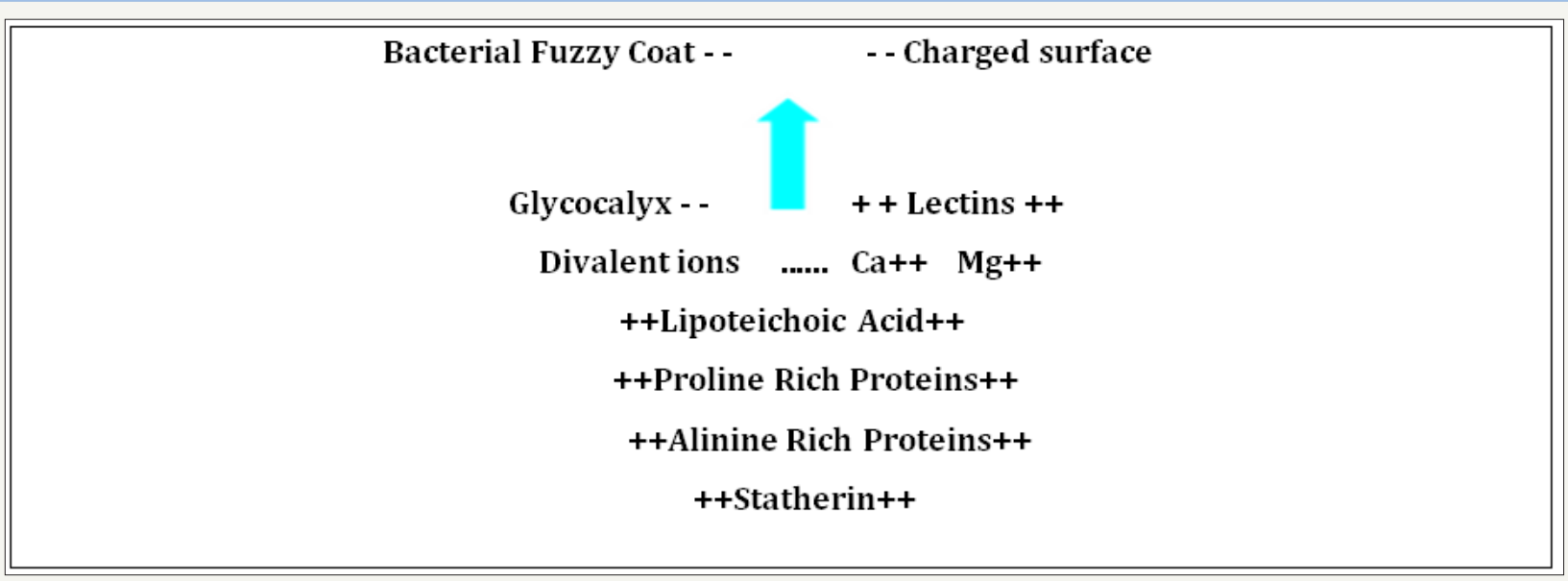

Figure 1: Primary mechanisms of binding attachment of negatively charged bacteria, to an amenable surface. The bacterial exopolymer glycocalyx (fuzzy coat) is negatively charged $(--)$; the arrow indicates where the positively $(++)$ charged molecules bind to the negative charges, and promote attachment of microbes to receptive surfaces [1].

\section{Natural organic polymer biofilms and health}

PE consists mainly of Gram positive bacteria, aerobic, exopolymer forming microbes. As the ecosystem matures it allows adherence of a whole host of different microbes becoming enmeshed with the exo-polymer matrix. In viable biological situations the bacterial clumps grow as adherent plaques in the matrix and are referred to as sessile colonies; when individual organisms or clusters 
separate from the base mass, they are called planktonic microbes. In humans transient bacteremia in the blood are mainly Gram +ve planktonic floaters (Streptococcus viridians and S. mutans), with other organisms as well. A septicemia has planktonic bacteria in the blood, but they multiply and grow and should they seed, affix to the endothelium of any blood vessels, they form subsequent sessile attached colonies. These early bacteria may grow exo-polymers that disallow antibiotics to work. In humans if an inflamed organ, like a heart-valve, or a metal prosthesis allows for attachment of gram positive microbes, a subsequent sessile colony of bacteria may develop from a bacteremia seeding the site. Sessile bacteria are extremely difficult to remove by chemotherapy with antibiotics. This among other indications is why in patients known to have large metal prostheses, or suffering from endocarditis, large bolus doses of prophylactic antibiotics are administered to them before any procedure causing bacteremia.

PE consists mainly of Gram positive bacteria, aerobic, exopolymer forming microbes. As the ecosystem matures it allows adherence of a whole host of different microbes becoming enmeshed with the exo-polymer matrix. In viable biological situations the bacterial clumps grow as adherent plaques in the matrix and are referred to as sessile colonies; when individual organisms or clusters separate from the base

\section{Synthetic plastic polymers, ecosystems and health}

The chemical composite units used for Biological Polymers BP, and Synthetic Plastic Polymers, SPP are totally different from each other. BP's use biological molecules, like saccharides to form polysaccharides; SPP use non-biological molecules, mostly derived from petro-chemical hydro-carbonaceous oil or gas, like ethylene and propylenes to form polymers like poly-ethyleneand polypropylene. The Hydrocarbons are processed at high temperatures under extreme pressures and polymerization occurs, leaving small pellets of polymer; the polymer plastic pellets are melted down into liquid and shaped into sheets, bags and objects. Injection molding and extrusion are the basis of global multibillion dollar industries manufacturing synthetic plastic products. No naturally occurring aquatic biological enzyme systems exist which can digest SPP into its original monomer subunits. Most Bio-P's are made up of monoand disaccharides into oligo- and poly-saccharides. Syn-PP use chemical industrial processes to polymerize a whole wide array of synthesized chemicals, (like poly-ethylene, or poly-propylene) to create new plastic materials with desirable properties. A rare land-based biological species of worm may digest some SPP. (ref Yu et al. 2015) But for the vast majority of SPPs', aquatic biological microbial enzyme systems to degrade SPP's into digestible subunits and chemical elements are exiguous. For example the BP cellulose is broken down by cellulase into metabolizeable glucose units, but SPP poly-ethylene and others, remains intransigent, and immune to disassembly into constituent elements forever. SPP's are globally used to make a variety of plastic products and many are retrieved and recycled. Globally SPP plastic packaging and use of SPP plastic bags has created a catastrophic polluting situation globally in waterways, lakes, seas and oceans. This is because the
SPP's may break up physically into progressively smaller pieces; SPP's are not bio-chemically decomposed at any level, not at the physical macroscopic or the chemical microscopic levels. Floating plastic bags pollute land-fills and accumulate in the open seas. These are mistaken for food like jelly fish, and are ingested by animals like turtles, whales and other sea creatures. Smaller SPP pieces, progressively break down to microscopic fragments (MP=micro-plastics, many derived from nanotechnology being used in cosmetics, medicine, fragrances and other products,) end up fouling and foiling the life-cycles of aquatic ecosystems, from filter feeders like oysters, clams, mussels and ocean diatoms, to bigger fish and huge sea mammals. SPP's are not metabolizeable and have no biological nutritional value. Consequently huge populations of aquatic ecosystems and life are being obliterated through hunger by the accumulation of SPP's as Micro-plastics in global water ways. Increased accumulation of SPP micro-plastics has become a major eco-disaster.

There are oceanic whirl pools called "GYRES," which trap huge collections of waste in their currents. There are five major oceanic gyres: North Pacific, South Pacific, North Atlantic, South Atlantic and the Indian Ocean. Some 800000 tons of plastic trash has accumulated, which is sixteen times more than was previously reported (2018); this polymer deposit is in the "Great Pacific Garbage patch" alone. Plastic- objects, plastic sheets, film, fishingnets, bottles, lids-packaging straps and ropes, plastic drinking straws by the billions,... all make up this plastic swamp of floating debris. This oceanic plastic has been accumulating since the 1960's and the polyethylene and polypropylene plastic polymer products, both collect and float around in the ocean-gyres as unusable, non biodegradable garbage.

The SPP also absorb polluting chemicals like lead, mercury and organic molecules like DDT and other organic phosphates used in agriculture. These are ingested with plastic particulates and add to the metabolic stress of marine life. Consequently huge populations of aquatic ecosystems and biology are being obliterated through hunger by the accumulation of SPP's as Micro-plastics in global water ways. Increased accumulation of SPP micro-plastics has become a major eco-disaster. Manufacturer responsibility for SPP is long overdue (2018) and biological degradable products must be embraced by all manufacturers, traders and consumers, to stop and reverse this imminent and compelling biological catastrophe. It may be feasible through genetic modification, to mutate a bacterial species or worms which could metabolize all synthetic plastics. This is a notion which is fraught with unknown dangers and may release devastating consequences on the biosphere.

\section{Discussion}

Some natural waters are reasonably safe to drink, but not all natural waters are absolutely safe. Abuse of SPP's and the resultant Micro-plastics (MP's) may well prove to be a major ecological crisis of catastrophic proportions for mankind unless policies are adopted immediately to eliminate promiscuous, disastrous and deleterious use of SPP's. 


\section{How can waterborne infection be prevented when polluted water filtration is absent?}

When situations arise, where no filtered municipal water is available, or when hiking or camping in the wild, boiling water for 10 minutes will eliminate most viable pathogens. Contact with chlorine or iodine at $2-3 \mathrm{mg} / \mathrm{L}$ for at least 2 hours will prove effective. Freezing does not eliminate pathogens, and ice from polluted water remains as infective as the ice itself. Some commercial products are Globaline, B-K, HTH, and Wesodyne are effective chemical disinfectants. Chloride of lime, using one teaspoon in 25-50 gallons of water, and at least one hour of waiting for the chemical to work, is affective. Sodium hypochlorite ( $5 \%$ concentration), ubiquitously available as laundry bleach, will also do the job.

Planktonic microbes are more vulnerable and prone to successful antiseptic controls as with chlorinating water supplies destined for municipal human consumption. Filters must be finely meshed for removing planktonic bacteria. Sessile, intra-biofilm microbial colonies are more challenging in humans as antibiotics will not be able to be as effective as needed because the sessile colonies may be protected by layers of exo-polymer. Also in municipal civically engineered water-storage and reticulations, sessile polymer colonies are difficult to totally eradicate through trace chemicals, but planktonic bacteria are effectively removed. Without chlorination PE's and CE's will form in pipes, water systems and plumbing reticulations. In Nature they form also on rafts, ship and boat hulls. Microorganisms within exo-polymeric biofilms (as buried 'sessile 'colonies,) appear to be less susceptible to biocides than their loose floating 'planktonic' counterparts. This is because the exo-polymers act as a filtering barrier that will not allow biocidal molecules to diffuse through in high enough concentration, to affect the polymer- enmeshed bacteria.

\section{Concluding remarks}

When treated municipal water is available, drinking raw natural water is not desirable. The disinfection of public water supplies by chlorination is among the most important advances and contribution to civilization by civil engineers. The deconstruction of exo-polymer formation and its subsequent behavior explains how and why pathogenic bacteria remain in natural waters and may be infective to mankind. Exo-polymers are also involved with pathogenic processes in humans. Development of tooth decay is controlled by regular oral hygiene techniques which physically remove early bacteria ecosystems or disrupt the exo-polymers with brushing, and flossing inter-dental stagnating areas. Eufluoridation of municipal drinking waters significantly reduces the prevalence of tooth decay. Prophylactic antibiotic use before surgeries reduces planktonic seeding and formation of sessile microbial colonies with consequent development of infections.

\section{Conclusion}

Water pollution by natural polymers and Synthetic plastics polymers both affect mankind. Clean, reliable, non-pathogenic water supply is essential for human survival and should be enshrined as a global human right to have access to healthy water. Pollution with polymer micro-plastics affects the whole foodchain for marine animals. Exo-polymers are important biological phenomena affecting world-wide biological ecosystems and human well being Use of synthetic plastic polymers need to be constrained to arrest pan-global pollution by micro-plastics.

\section{References and Resources}

1. Touyz LZG (2017) The pathophysiology of oral biofilms and its relation to initial gum disease and caries. Journal of Dentistry, Oral Disorders \& Therapy 5(4): 1-6.

2. Frobisher (1968) Water supplies and waste disposal, ( $8^{\text {th }}$ edn). Fundamentals of Microbiology, pp. 517-530.

3. Yang Y, Yang J, Wu WM, Song Y, Gao L, Yang R (2015) Biodegradation and mineralization of polystyrene by plastic-eating mealworms: Part 1 : Chemical and physical characterization and isotopic tests. Environ Sci Technol 49(20): 12080-12086.

4. Gavin L. Explains how biofilms work with bioremediation by mapping out fundamental principles of biofilm research. Presents basic steps in the important role of polymer biofilms in Nature. Biofilms in Bioremediation: Current Research and Emerging Technologies.

5. Romaní AM, Guasch H, Balaguer MD (2016) Aquatic biofilms: Ecology, water quality and wastewater treatment. Biotechnol Agron Soc Environ.

6. Gavin L, Gillian Lewis D. Gives update/review of specific locationinteractions referred to in a quorum- paper. Microbial Biofilms: Current Research and Applications.

7. Jerzy D. Nacute deconstructs and clarifies biology of recycling. Microbial Biodegradation: From Omics to Function and Application.

8. Martin Wilkinson G. Flow cytometry in microbiology: technology and applications.

9. Markus K, Sören S. Describes chemical tools used for research. MALDITOF Mass Spectrometry in Microbiology.

10. Jürgen M. Insights into global warming and consequences at all levels. Climate Change and Microbial Ecology: Current Research and Future Trends.

11. Diana M. Describes inter-relationships of ecosystems. Metagenomics of the Microbial Nitrogen Cycle: Theory, Methods and Applications.

12. Lesley AO, Penny RH. A perspicacious oversight of role of microbes in pan-biology. Microbial Ecological Theory: Current Perspectives.

13. Robertson BD, Brendan WW. Appraises control of microbes in municipal waters. Systems Microbiology: Current Topics and Applications.

14. James Moir WB. Explains how nitrogen in fertilizer runoff pollutes water reserves. Nitrogen Cycling In Bacteria: Molecular Analysis.

15. Publications on environmental microbiology: check out Wikipedia. General reports.

16. Jambeck JR, Geyer R, Wilcos W, Siegler R (2015) Plastic waste inputs from land into the ocean. Science 347(6223): 768-771.

17. Briggs H (2018) Plastic patch in Pacific Ocean growing rapidly. Reports on increasing size of oceanic plastic garbage. 
Creative Commons Attribution 4.0 International License

For possible submissions Click Here

\begin{tabular}{|l} 
RMES $\begin{array}{c}\text { Research in } \\
\text { Medical } 8 \\
\text { Engineering } \\
\text { sciences }\end{array}$ \\
Benefits of Publishing with us \\
- High-level peer review and editorial services
\end{tabular}

